REVISTA DE ESTUDOS EM ARTES CÊNICAS

E-ISSN 2358.6958

\title{
Memórias dissidentes: Nossa Odisseia, de Christiane Jatahy
}

Sílvia Fernandes

Para citar este artigo:

FERNANDES, Sílvia. Memórias dissidentes: Nossa Odisseia, de Christiane Jatahy . Urdimento - Revista de Estudos em Artes Cênicas, Florianópolis, v. 3, n. 42, dez. 2021.

doi DOI: http:/dx.doi.org/10.5965/1414573103422021e0212

Este artigo passou pelo Plagiarism Detection Software | iThenticate 


\title{
Memórias dissidentes: Nossa Odisseia, de Christiane Jatahy
}

Sílvia Fernandes ${ }^{1}$

\begin{abstract}
Resumo
Foram analisados no artigo os espetáculos ítaca (2018) e O agora que demora (2019), criados pela encenadora Christiane Jatahy. Enquanto teatros performativos, híbridos e políticos transitam entre zonas artísticas, culturais e geográficas de fronteira. No uso de testemunhos de refugiados e na criação de arquivos documentais os dois trabalhos se relacionam a alguns pressupostos definidos por Rebecca Schneider como atos e modos incorporados de memória.
\end{abstract}

Palavras-chave: Memória incorporada. Testemunho. Arquivos performativos.

\section{Dissident Memories: Our Odyssey, by Christiane Jatahy}

\begin{abstract}
The text analyzes the spectacles itaca [Ithaca] (2018) and O agora que demora [The now that's delayed] (2019), created by the director Christiane Jatahy. Recognized for the creation of a performative, hybrid and political theatre, the artist transits between cultural and geographical frontier zones. Based on assemblages and repetitions the artist's performative practices relate to certain proposals defined by Rebecca Schneider, especially the conception of "archives as act" and embodied modes of memory.
\end{abstract}

Keywords: Embodied memory. Testimony. Archives as act.

\section{Memorias disidentes: Nuestra Odisea, por Christiane Jatahy}

\begin{abstract}
Resumen
En el artículo se analizan los espectáculos ítaca(2018) y O agora que demora (2019), creados por la directora Christiane Jatahy. Como teatros performativos, híbridos y políticos, transitan entre fronteras artísticas, culturales y geográficas. En el uso de testimonios de refugiados y la creación de archivos documentales, las dos obras se relacionan con algunos supuestos definidos por Rebecca Schneider como actos y modos de memoria encarnados.
\end{abstract}

Palabras clave: Memoria encarnada. Testimonio. Archivos performativos.

${ }^{1}$ Pós-doutoramento na Universidade de Paris 8, em 2003, com supervisão de Patrice Pavis, e na Universidade de Lisboa, em 2009. Doutorado em Artes Cênicas pela Universidade de São Paulo (1988). Mestrado em Artes Cênicas (USP-1995). Graduada em Artes Cênicas (USP-1978). Professora titular sênior do Programa de PósGraduação em Artes Cênicas da Universidade de São Paulo. silvia.fernands@terra.com.br

(9) http://lattes.cnpq.br/5393824704722004 (iD) https://orcid.org/0000-0002-1988-1771 
Este texto analisa o díptico Nossa Odisseia, composto pelos espetáculos Ítaca (2018) e O agora que demora (2019), criados pela encenadora Christiane Jatahy com a Companhia Vértice de Teatro. A artista é reconhecida pela criação de um teatro performativo, híbrido e político, que transita entre zonas artísticas, culturais e geográficas de fronteira. Trabalhando na confluência entre teatro e cinema, a companhia combina tecnologias de imagem a testemunhos, justapostos com base em assemblages e repetições. Caracteriza-se pela travessia interdisciplinar, com ênfase na fronteira entre o vivo e o mediado, construindo um dispositivo de colaboração entre mídias que justapõe imagem, som, movimento, espaço e texto. Além do mais, usa práticas performativas que se relacionam a alguns pressupostos definidos por Rebecca Schneider, especialmente no que se refere à concepção de arquivos como atos e modos incorporados de memória (Schneider, 2011).

Schneider é representante da vertente dos estudos da performance cultural (cultural performance) que se distancia das abordagens influenciadas pela linhagem da antiarte, da crítica à representação e da arte da performance (performance art). Analisando esses eventos, cujo ápice aconteceu entre as décadas de 1960 e 1980, vários estudiosos da área ressaltavam a experiência ao vivo, sem mediação nem repetição, realizada no presente da cena. Era o caso das criações de artistas como Marina Abramovich, Vito Acconci, Gina Pane ou Chris Burden, por exemplo, que na defesa da efemeridade e da independência em relação à reprodução pretendiam contrapor-se a dispositivos institucionais como museus e mercado de arte. A troca entre performers e espectadores feita em tempo real, o risco da situação de exposição explícita dos artistas, o desafio aos limites do corpo especialmente na body-art e a defesa da experiência efêmera e irrecuperável tinham como pressuposto a impossibilidade da repetição (Glusberg, 1987; Goldberg, 1988). ${ }^{2}$

\footnotetext{
${ }^{2}$ As análises voltadas especificamente para a performance artforam desenvolvidas inicialmente por Rose Lee Goldberg e Jorge Glusberg e continuadas por Josette Féral e Érika Fischer-Lichte, entre outros. Os estudiosos mencionados concordam que a arte da performance se atém à instância artística e não pode ser separada das práticas estéticas que passaram a se desenvolver em vários cantos do mundo especialmente a partir dos anos 1960, como o happening, a action painting, a live art, a arte conceitual e a body art. Interessada na experiência corporal e na ação do artista em situações extremas, a arte da performance visa exatamente a desestabilizar o cotidiano por meio da transgressão e da ruptura, promovendo ações artísticas marcadas pela diferença.
} 
A defesa da performance como experiência imediata e centrada na presença viva foi explicitada em diversos escritos, como é o caso do influente Unmarked, de Peggy Phelan, publicado em 1993. No livro, a autora sustenta que a arte da performance é uma prática específica exatamente por seu caráter de evento irrepetível, impermanente, que não pode ser reproduzido nem gravado. "A única vida da performance é o presente. A performance não pode ser salva, registrada, documentada [...]: se fizer isso, torna-se outra coisa e não performance" (Phelan, 1993, p.146). ${ }^{3}$

Com o avanço do século XXI a mudança do paradigma de análise da performance torna-se cada vez mais evidente. E Rebecca Schneider responde a essa alteração criticando, por exemplo, a concepção de Phelan, por considerá-la excessivamente centrada na metafísica da presença que fetichiza o momento singular da apresentação (Schneider, 2012, p.71). Mas a crítica de Schneider não se dá de forma isolada. Ao contrário, responde à tendência recorrente, especialmente a partir do princípio dos anos 2000, que une diversos artistas na tentativa de reproduzir seus trabalhos anteriores a partir da documentação das apresentações ao vivo. É o caso emblemático de Marina Abramovic em Seven easy pieces, reenactment de performances de Bruce Nauman, Vito Acconci, Valie Export, Gina Pane e de dois de seus trabalhos anteriores, Lips of Thomas e Entering the other side, todas apresentadas inicialmente nas décadas de 1960 e 1970. A artista justifica a repetição - ou a re-performance ou o reenactment - afirmando que "'a única forma real de documentar uma performance é a própria re-performance" (Abramovic, 2007, p.11). ${ }^{4}$

No período imediatamente anterior à publicação dos estudos de Schneider, Richard Schechner foi um dos responsáveis por um giro cultural na análise das práticas performativas. Ancorado nas pesquisas antropológicas de Victor Turner, passa a defender que o comportamento restaurado é a noção básica da performance. (Schechner, 1985, p.36.). Além disso, propõe o modelo do comportamento duplamente atuado (twice-behaved behavior) para sublinhar que

\footnotetext{
3 Performance's only life is in the present. Performance cannot be saved, recorded, documented [...]: once it does so, it becomes something other than performance. (Tradução nossa)

${ }^{4}$ the only real way to document a performance art piece is to re-perform the piece itself. (Tradução nossa)
} 
todos os eventos são compostos de atos de citação por incorporarem algo que aconteceu anteriormente. Para Schechner, a duplicidade comportamental (twicebehavedness) de todo ato comunicativo é necessária à ação social e o reenactment é um modo vital de recordação coletiva. ${ }^{5}$

Logo em seguida, em trilha semelhante de argumentação, Joseph Roach vincula a performance à prática de repetição e transformação, por considerá-la um evento não original que sempre substitui algo preexistente. Expandindo a análise para o campo social, Roach considera a performance o processo por meio do qual as condições de existência coletiva tomam forma (Roach, 1996). De certo modo, a posição é compartilhada por Philipp Auslander, que além de enfatizar o caráter de repetição de toda performance vai além, recusando-se a fazer qualquer distinção binária entre vivo e mediatizado. Em Liveness. Performance in a mediated culture argumenta que o imediato não antecede a mediação, mas deriva da relação com ela. "O vivo só pode existir em uma economia da reprodução", observa, lembrando que a performance ao vivo geralmente é usada para a criação de re-performances, o que seria uma prova de que não se pode separar o vivo do gravado (Auslander, 1999, p.53-54; Auslander, 2012). ${ }^{6}$

É a partir de Auslander que Rebecca Schneider desenvolve a noção de "convocação" (hail) ou "chamamento gestual" (gestural call), que usa para embasar a ideia de que a performance tem um registro estendido capaz de instaurar um tempo suspenso como um eco, que antecipa a recepção do espectador ou participante do encontro. O “chamamento gestual” é, portanto, relacional e expandido no tempo e no espaço, já que as fronteiras do vivo são porosas, garantindo uma troca que atravessa várias temporalidades e abre brechas em que a resposta do receptor pode incluir-se. Segundo a autora, a "convocação" antecipa uma resposta ao evento vivo que, na verdade, já faz parte dele. Portanto, a

${ }^{5}$ O campo de estudos da performance cultural consolidou-se nos Estados Unidos nos anos 1970 e 1980 , especialmente com a equipe liderada por Schechner na Universidade de Nova York. O pesquisador americano afirma que os estudos ligados à antropologia e à sociologia foram responsáveis pela criação de um novo paradigma, que respondeu aos limites dos métodos de análise da performance artística, que não conseguiam dar conta da radical mudança no panorama cultural que ocorreu no último terço do século XX. Ao definir a performance como ação Schechner aplica a categoria a todos os aspectos da vida. "Doing é a atividade de tudo que existe, desde os quarks até os seres humanos”, afirma em Performance Studies. An introduction. New York and London: Routledge, 2006, p.123.

${ }^{6}$ The live can exist only within an economy of reproduction. (Tradução nossa) 
performance como hail ou como gesto circula performativamente no encontro entre performers e espectadores (Schneider, 2017, p.77-79).

O breve apontamento de algumas concepções de Schneider torna evidente que seus estudos, bem como os de outros pesquisadores contemporâneos da área, são responsáveis por reinscrever a performance em uma cultura da repetição. Talvez por isso, na tentativa de explicitar melhor seus pontos de vista, a ensaísta evite ao máximo as antinomias, especialmente as que opõe presença e ausência, pois parte do pressuposto de que toda performance é não-original e citacional. E exatamente por isso é possível relacioná-la a um novo modo de arquivo, o que Schneider faz de modo exemplar. Nessa relação, e seguindo a trilha de Jacques Derrida, recupera a etimologia da palavra arquivo a partir de seu uso na cultura grega. De fato, Derrida já demonstrara que o sentido do arquivo tradicional vem de arkheîon, a casa dos magistrados que comandam, guardam, protegem e determinam o modo de organização, leitura e apreensão de documentos estritamente materiais e quantificáveis. Assim, cabe aos arcontes que detém o poder político o direito de fazer ou representar a lei, bem como de guardar os documentos oficiais. A partir daí, o filósofo conclui que a função de arquivar é essencialmente patriarcal e, portanto, não é possível existir poder político sem controle do arquivo e da memória. Daí decorre um dos traços próprios às tradições europeias, que é justamente sacramentar e preservar a memória oficial da cultura e, desse modo, garantir a dupla relação entre conservação e instituição (Derrida, 1995, p.12-15).

Com base no argumento de Derrida, Schneider conclui que a escrita da memória ligada aos arquivos tradicionais é necessariamente falha, pois é um modo de governo contra os povos cuja memória não se ampara no documento material, mas em formas de transmissão parciais, não originais, repetidas e contaminadas. Os arquivos coloniais são um bom exemplo do uso de documentos como armas do Império para desvalorizar o conhecimento local dos povos colonizados, em geral reconhecidos por práticas performativas como a oralidade, a recitação ao vivo, o gesto repetido e o ritual. Essas práticas de transmissão estão ligadas a modos incorporados de produção de arquivos, capazes de atualizar a memória em modos de vida impermanentes, que se desvanecem e reaparecem de forma 
confusa e eruptiva. "A performance joga com atos sedimentados e significados espectrais que assombram o material em constante interação coletiva, em constelação, em transmutação", observa Schneider (2011, p.102). ${ }^{7}$

Diana Taylor é outra analista da performance cultural que defende pressuposto semelhante ao ressaltar que as culturas europeias privilegiam a literatura em detrimento da oralidade ou, de acordo com sua terminologia, o arquivo em prejuízo do repertório. Segundo a autora, a performance é um modo de preservar a memória por meio de atos corporais de repetição que chama de repertório e distingue do arquivo, composto de documentos escritos que desconsideram as práticas envolvidas na transmissão corporal mnemônica. Segundo Taylor, a geopolítica historicamente alinhou os colonizadores europeus ao arquivo e ao poder hegemônico, enquanto os colonizados "primitivos" sempre foram associados à performance viva, às tradições de transmissão oral e aos modos incorporados de preservar o passado. Para Taylor, eles constituem formas contra-hegemônicas de narrar a história e é exatamente por esse motivo que não são reconhecidos como indicadores válidos da história (Taylor, 2003).

Na mesma linha de Taylor, Schneider valoriza as formas incorporadas da memória que se apresentam na fala ao vivo, no gesto repetido, na ação ritual e em outros modos desvalorizados de performance, que considera "arquivos como atos". "A memória pode habitar um corpo", argumenta a autora, lembrando que os corpos são sites em que passado e presente negociam a transmissão memorial ao vivo. ${ }^{8}$ Assim, um testemunho ou um encontro entre corpos engajados na performance podem funcionar como incorporações da memória coletiva e, por isso mesmo, questionar a noção tradicional de arquivo. Em seu argumento, Schneider recupera a terminologia de Foucault para valorizar a "contra-memória" que se manifesta em atos capazes de performar ao vivo arquivos contrahegemônicos (Foucault, 1969, p. 129; Schneider, 2012, p.141).9

7 performance plays 'sedimented acts' and spectral meanings that haunt material in constant collective interaction, in constellation, in transmutation. (Tradução nossa)

${ }^{8}$ The memory can be housed in a body. (Tradução nossa)

${ }^{9}$ Para a escrita da história, a genealogia de Michel Foucault concentra-se nas descontinuidades e nas rupturas, priorizando temas marginais e contrapondo-se à perspectiva tradicional de organização contínua e linear dos fatos. Uma das ideias fundamentais do filósofo é a noção de contra-memória, counter-memory, 
Como se vê, a argumentação de Schneider altera as noções convencionais de arquivo ao mostrar que a performance pode funcionar como um tipo de transmissão corporal da memória que reverbera e ressoa no espectador (Schneider, 2012, p.75). Nesse sentido, ela não desaparece, mas se mantém nos atos sedimentados no imaterial da vida, que assombram as interações coletivas. Portanto, a performance pode ser considerada uma instância de conhecimento incorporado que, de certa forma, repete o passado e torna possível ao espectador testemunhar atos de reelaboração de uma história incompleta, em movimento no presente que engaja aquele que participa do evento em uma espécie de negociação com o futuro. (Schneider, 2011, p. 35). Assim, o espectador pode fazer a travessia de diversos momentos históricos que conectam passado, presente e futuro sem respeitar uma sequência temporal linear. Além de experimentar múltiplos sites com estratos de "memória multidireccional" que viabilizam a criação de um "cruzamento complexo" e oscilante entre passado e presente (Rothberg, 2013; Schneider, 2011, p. 35).10

\section{Nossa Odisseia}

Pode-se dizer que os trabalhos de Christiane Jatahy são fruto de uma postura dissidente em relação à cultura de arquivo tradicional. Especialmente porque a artista cria arquivos durante as apresentações, tanto na via da hibridização entre performance ao vivo e imagens gravadas, com uso de cinema e vídeo na reprodução das cenas, quanto pelo recurso a testemunhos e à memória incorporada dos performers. No caso de suas criações mais recentes, os indivíduos funcionam como arquivos vivos de texto, comportamento e experiência. (Martin, 2010) $)^{11}$

resultante da reatualização de eventos recompostos de forma diferente, com os elementos iniciais repetidos mas rearranjados. É justamente o rearranjo que problematiza os fatos, permitindo nova avaliação e construção da história (Foucault, 1969).

10 Tradução da autora a partir do original "multidirectional memory" e "complex crosshatch".

${ }^{11}$ Ainda que a oscilação entre real e ficcional seja uma constante na trajetória artística de Christiane Jatahy, não é intenção deste texto desenvolver a questão. É possível observá-la, por exemplo, nas performances dos atores, próximas da informalidade cotidiana, permeadas de elementos autobiográficos, com ênfase na autenticidade e nas falas coloquiais, além do endereçamento explícito ao espectador, frequentemente 
De fato, a hibridização entre performance ao vivo, depoimentos e imagens gravadas é uma constante na trajetória de Christiane Jatahy. O depoimento já aparece, por exemplo, em Conjugado, estreado em 2004, em que a artista recorre a entrevistas com mulheres solitárias, moradoras de pequenos apartamentos de um só cômodo, para criar uma dramaturgia em que as dimensões documental e ficcional têm seus limites deliberadamente borrados. O impulso para se situar na fronteira entre performance e testemunho reaparece em $A$ falta que nos move ou todas as histórias são fiç̧ão, espetáculo de 2005, posteriormente filmado em 2008, em que amigos da mesma geração evocam, em confissões autobiográficas, a memória familiar e a perda de pessoas próximas. Nesses trabalhos, Jatahy investiga a fronteira entre os campos do teatro e das tecnologias de imagem, importante em futuras criações como Julia, livremente concebida a partir de Senhoria Júlia, de Strindberg, em que desenvolve uma proposta de filmagem ao vivo. Construído no diálogo intenso entre as linguagens do teatro e do cinema, o espetáculo inclui filmes realizados previamente e exibidos durante a apresentação, em que também há captação de imagens ao vivo. O diretor de fotografia opera a câmera em cena, dividindo o palco com os atores ao longo de todo o espetáculo para mostrar trechos ocultos da ação, visíveis graças à mediação da imagem (Da Costa, 2017)

Procedimento semelhante reaparece em E se elas fossem para Moscou (2014), baseado em As três irmãs, de Tchekhov. Concebido paralelamente a um documentário e uma instalação em vídeo, Utopia.doc, recorre a testemunhos de exilados, especialmente migrantes que aspiram a uma vida renovada em outro lugar, como acontece com as personagens tchekhovianas. A proposta mantém-se em $A$ floresta que anda (2016), instalação-performance inspirada em Macbeth de Shakespeare, ambientada em um galpão com quatro telas suspensas em que são projetados testemunhos de repressão, violência, preconceito racial e assassinatos perpetrados por contingentes de uma suposta "polícia pacificadora" atuante nas favelas cariocas.

Em certo sentido, o projeto Nossa Odisseia é a radicalização das vertentes anunciadas nesses trabalhos. Composto pelos espetáculos ítaca e 0 agora que 
demora, o díptico mantém os procedimentos de hibridização entre teatro e cinema e a ênfase na performatividade, mas a encenadora intensifica o uso de testemunhos, optando pela narrativa oral como meio de resgate da memória coletiva. Nesse caso, na via dos depoimentos, Jatahy recupera a história recente dos refugiados, que associa à busca de seus antepassados na Amazônia brasileira.

Parece evidente que a escolha do refugiado como foco central de Nossa Odisseia é a opção política da encenadora para projetar uma memória multidirecional, que não se restringe à história oficial (Rothberg, 2013). Sem dúvida, a figura marginal do refugiado desestabiliza a antiga tríade estado-nação-território, como nota Giorgio Agamben ao lembrar que ele coloca em xeque os fundamentos da cidadania ligados ao nascimento em determinado país. Como se sabe, Agamben sublinha o status paradoxal dos campos de refugiados, que considera um trecho de território colocado fora da norma jurídica e, portanto, um espaço de exceção entre as nações (Agamben, 2002).

Esse território sem nação é explorado por Jatahy na projeção cênica e narrativa da errância dos apátridas. Na tentativa de encontrar um equivalente ficcional para a crise migratória, a encenadora recorre à Odisseia, associando os refugiados a Ulisses em sua longa viagem de retorno a Ítaca e às dúvidas sobre a possibilidade de voltar para casa.

Na verdade, a escolha da epopeia de Homero é compreensível. Viagem mítica por excelência e verdadeiro paradigma da errância, liga-se à memória no duplo sentido de narrar atos memoráveis e ser narrativa oral que facilita a memorização. Além do mais, na assemblage tecida pelo rapsodo grego, o tempo de retorno do herói à terra natal define-se pelo "ainda não" ou, segundo Jatahy, por um "agora que demora" capaz de sintetizar o problema nuclear da Odisseia: saber se Ulisses consegue retornar ao território de origem, o nostimos (Cassin, 2011, p.103-106)

Sem dúvida a esperança de retorno à terra natal perpassa os espetáculos do díptico, que preservam traços da narrativa grega, com uso de passagens literais da epopeia entremeadas a testemunhos de refugiados entrevistados pela encenadora após travessia do Mediterrâneo. O que preside a associação é a compreensão da continuidade e da simultaneidade da história e das formas de sua atualização por 
meio da repetição e da transformação performativas. Trata-se do "trabalho imaterial de passagem" da obra de arte, em que questões semelhantes retornam para se atualizar (Hantelmann, 2010, p.137; Schneider, 2011, p.130-135).

Na primeira parte do projeto, Ítaca, Jatahy consegue transformar o exílio em matéria cênica ao conceber um dispositivo com longas cortinas que dividem o palco de modo a criar uma cena bifronte, que funciona como território dividido em que três atrizes brasileiras e três atores francófonos performam os duplos Penélope/Calipso e Odisseu/pretendentes. Nas falas em português e francês a encenadora mimetiza a barreira da língua para mostrar a incômoda posição fronteiriça do estrangeiro, do refugiado, do migrante. O que se percebe é que no vaivém do texto entre as duas línguas os performers apresentam estados mutantes de Ulisses, Penélope e Calipso, além de situarem a posição de desterro.

Talvez por isso os atores e as atrizes não sejam definidos por seu enraizamento identitário nem pela trajetória subjetiva de supostas personagens. $\mathrm{Na}$ verdade, são figuras que se constroem pela itinerância constante, uma verdadeira migração de um lado a outro do palco que manifesta, espacialmente, seu desencaixe territorial e social. No embate concreto entre os corpos, em sequências assustadoras de agressão dos homens contra as mulheres, a atenção dos espectadores é despertada para a transmissão corporal de afetos e sentidos entre os sujeitos que performam e assistem. A atmosfera cênica literalmente atravessa as fronteiras dos corpos para atingi-los e permitir que experimentem o afeto de modo "intertemporal, interespacial e intergeográfico" (Schneider, 2011, p.36)..$^{12}$

Os fluxos narrativos compostos por passagens da Odisseia e depoimentos dos refugiados circulam performativamente e convivem com imagens captadas por câmeras operadas ao vivo pelos atores, projetadas pontualmente na

12 O "affective turn" apontado por Brian Massumi resiste ao binário corpo/texto e prioriza a atmosfera entre os corpos, o deslizamento e a negociação entre eles. Para o filósofo, o afeto consegue atravessar esses corpos sem respeitar fronteiras materiais. Trata-se de uma transmissão feita por meio das trocas corporais que literalmente atingem o espectador. $\mathrm{Na}$ referência a Massumi, Schneider afirma que o afeto pode circular em vestígios materiais ou gestuais transmitidos por uma canção, uma narrativa ou um encontro entre pessoas. Assim, tocar ou ser tocado tornam-se transmissores de afetos, que podem viajar entre os corpos no tempo e no espaço e indicar o nível libidinal do engajamento. (Schneider, 2017, Massumi, 2015) 
tela/cortina. Assim, a memória recente dos refugiados é hibridizada ao texto arcaico de Homero, criando uma síncope temporal que se abre no intervalo entre testemunho e performance, oralidade e multimídia, local e global. Intercaladas aos vídeos gravados pelos próprios performers, as cenas ao vivo acabam projetando uma travessia entre tempos e espaços, vivo e documental.

É possível perceber que a intrincada assemblage cênica é movimentada pela repetição constante de gestos, falas, imagens, movimentos e reconfigurações. À medida que o espetáculo avança, os atos de retorno e reelaboração são cada vez mais intensificados. E culminam na passagem em que o público é convidado a migrar para a plateia do outro lado da cortina, onde as cenas recomeçam para outro grupo de espectadores, numa espécie de re-performance dos episódios anteriores.

Viabilizadas por deslizamentos entre a presença dos atores no palco, as imagens projetadas na tela/cortina, a narrativa dos testemunhos de refugiados e os excertos da epopeia de Homero, as repetições reaparecem sempre reconfiguradas e não cessam de alterar a situação cênica, criando um jogo de metamorfoses que mergulha o espectador em uma "dimensão especular vertiginosa”, capaz de desestabilizar sua posição (Triau, 2017, p.54). E, ao mesmo tempo, definem uma zona fronteiriça e descontínua que Erika-Fischer Lichte chama de situação liminar (betwixt ou betweeness) responsável por desencadear uma multi-estabilidade perceptiva (Fischer-Lichte, 2008).

O espetáculo termina com a abertura da cortina que separava os dois lados da cena, seguida de paulatina inundação do palco com água que dissolve as fronteiras demarcadas pelo dispositivo e, aos poucos, submerge câmeras e atores na sugestão de afogamento. O recurso remete à morte dos migrantes em seus barcos precários no Mediterrâneo, além de evocar a zona instável característica da situação de fronteira do refugiado. Ainda que parcialmente submersos, os performers continuam flagrados pelas câmeras, que projetam suas imagens deformadas. É perceptível que a distorção dos corpos, a dissolução vertiginosa do espaço, o desmanche do arranjo cênico desenham um palimpsesto de imagens, vestígios e traços anteriores. O procedimento torna o tempo visível e assegura, simultaneamente, o desaparecimento e a preservação. Trata-se de um dispositivo 
exemplar para a performance da memória (Rothberg, p.48). ${ }^{13}$

\section{O agora que demora}

Os testemunhos que aparecem pontualmente em Ítaca retornam e ganham primeiro plano em O agora que demora. O dispositivo central do espetáculo é uma enorme tela de cinema instalada em toda a extensão do palco, com mesas de controle na lateral onde a encenadora faz a edição ao vivo de um documentário com refugiados que filmou em cinco países. Ela edita, corta as cenas e muda a dinâmica das sequências na presença do público, transferindo o dispositivo de repetição para o cinema, já que o filme é refeito a cada apresentação.

Durante os quatro meses de filmagem do documentário, entre setembro e dezembro de 2018, a artista trabalhou com o Freedom Theater, criado pelo israelense Juliano Mer Khamis no campo de Jenin, onde vivem os palestinos exilados em sua própria terra. No vale de Beka, no Líbano, a artista conviveu com os sírios que criaram uma série de pequenos campos onde vivem em situação terrível. Atores exilados da Síria que desenvolvem ações artísticas nesses campos participam do filme e do espetáculo, como é o caso de um dramaturgo filmado na planície de Beka, onde permanece sitiado por não conseguir visto nas embaixadas ocidentais. Em Johanesburgo, na África do Sul, o Hillbrow Theatre abriu suas portas para o contato com as comunidades vindas do Zimbawe e do Malawi. Na Grécia, a diretora entrevistou exilados vindos especialmente do Iraque e da Síria, torturados por seu regime.

É interessante perceber como Christiane Jatahy consegue reunir o exílio dos refugiados à situação dos povos da floresta Amazônica que, como eles, perderam seus direitos e foram obrigados a deixar suas terras destruídas pelo desmatamento encorajado pelo governo de ultradireita de Jair Bolsonaro. A relação foi possível porque, na concepção da encenadora, a Amazônia é “o

\footnotetext{
13 Michael Rothberg menciona a técnica de associações visuais multidirecionais, que permite aos artistas justapor histórias e paisagens que se estendem para além do estado-nação. Para o autor, a circulação transnacional da memória em contextos transculturais é um meio de lembrar o passado e partilhar eventos que não vivemos (Rothberg, 2013, p.44-46).
} 
epicentro do desastre que estamos prestes a viver a nível mundial" (Sourd, 2019, p.19). Para a artista, a situação política brasileira de autoritarismo e destruição das conquistas sociais, de cerceamento da cultura e desmantelamento da educação, de desmatamento crescente da floresta amazônica e expulsão dos povos originários estaria, figurativamente, próxima da Ítaca de Ulisses dilapidada pela voracidade e pela rapinagem dos pretendentes de Penépole.

No documentário, exibido na imensa tela do palco, atores-refugiados vivendo em campos na Grécia, no Líbano, na Palestina e na África do Sul, além de indígenas da etnia Kayapó, leem passagens da Odisseia de Homero em sua língua, intercaladas aos próprios testemunhos. O dispositivo torna possível a projeção de uma verdadeira polifonia de vozes que lamentam a perda da família, do país e das terras que deixaram para trás, na narrativa de odisseias singulares, às vezes banais, mas sempre traumáticas. O impacto vem do fato de os relatos não se ligarem à história oficial, nem recorrerem a análises políticas e sociais do contexto. São fluxos orais de subjetividade que refletem memórias íntimas, autobiográficas, capazes de engajar o espectador pela via do endereçamento direto, além de remeterem ao contexto dos campos de refugiados com um grau acentuado de autenticidade (Forsyth e Megson, 2009, p. XII). Pode-se dizer que essas vozes compõem uma espécie de coralidade feita de reminiscências autobiográficas que constituem atos de reatualização da memória (Schneider, 2011, p.6).

A primeira parte de O agora que demora começa com imagens de uma mesa de banquete no Líbano onde é narrado o episódio do Ciclope. Na edição feita ao vivo, a diretora intercala a leitura das desventuras de Ulisses à narrativa de um refugiado sobre sua fuga da Síria, justaposta a uma luta armada na Palestina. O procedimento permite que os testemunhos individuais se misturem a passagens da epopeia para confundir presente e passado em uma multi-temporalidade ostensiva. O espetáculo oscila dos trechos filmados à performance dos refugiados que participam da apresentação ao vivo, na plateia, sentados entre os espectadores. Em diversos momentos eles levantam-se no meio do público para retomar a narrativa iniciada no documentário. É o caso da jovem atriz Yara Ktaish, que deixou a Síria para estudar teatro e voltou em 2015 para enfrentar uma sucessão de prisões inexplicáveis, até conseguir exilar-se no campo de refugiados 
onde vive há seis anos. Vista no filme, Yara reaparece na plateia como se tivesse atravessado a tela e abolido as fronteiras que a constrangiam para continuar seu testemunho entre os espectadores, com o rosto em close filmado pelo cameraman a seu lado e projetado no palco/cinema. Assim, na tela e na plateia a refugiada e a performer contracenam e associam o tempo cinematográfico do passado ao tempo performativo do presente, implicando os espectadores em um complexo cruzamento temporal (Schneider, 2011). Desestabilizado, o espectador não tem certeza se está no agora do presente performativo ou no passado do campo de refugiados, ou em ambos, diante de uma testemunha que sai do filme para questioná-lo.

O testemunho de Yara na plateia é respondido, na tela, por um ator iraniano filmado com o plano fixo do mar Mediterrâneo ao fundo e com tanques de guerra nas laterais. Ele relata o cansaço de ter de repetir sempre a mesma história e se justifica afirmando: "Meu erro foi ter nascido no Oriente Médio". É mais um indício do que acontece em todo o espetáculo, em que a crise migratória é desprovida de seus aspectos macroeconômicos para assumir uma dimensão subjetiva. A verdade é que a experiência singular está no núcleo dessa encenação performativa, que interpela o espectador com o conhecimento incorporado dos refugiados e dos performers. Em última instância, os testemunhos visam ao questionamento ético.

É o que acontece, por exemplo, com o testemunho da performer Fepa Teixeira, que narra a fuga de seu avô da ditadura de Salazar em Portugal, para se refugiar em São Paulo em 31 de março de 1964, exatamente a data do golpe que instaurou a ditadura militar de 21 anos no país. A fala é retomada por um ator belga que relata o exílio de seus pais durante a 2ª. Guerra Mundial, em 1940, e ressoa no depoimento da artista sueca cujas identidades múltiplas não the permitem uma definição de nacionalidade. A esses relatos se junta a odisseia pessoal da própria Christiane Jatahy em busca de vestígios do avô desaparecido na floresta amazônica. Cabe ao dispositivo multiforme e multimídia viabilizar o cruzamento de temporalidades e espacialidades e incrementar o diálogo entre o que se passa no filme e o que os atores performam no presente da cena. Assim, uma festa na Síria ressoa e se repete na África do Sul, onde refugiados na tela contracenam com performers na plateia do teatro, para terminar em uma dança que envolve os 
espectadores. Seguindo o mesmo princípio, um testemunho no Líbano ecoa na floresta amazônica. O mecanismo de justaposição permite que eventos do passado e do presente sejam examinados e reconsiderados por performers e espectadores em transmissão corpo-a-corpo que, na via do endereçamento direto, engaja-os na negociação de novas versões da memória social. Nesse caso, o teatro se transforma em fórum público de discussão do passado recente (Wilmer, 2018, p.84).

Percebe-se que as novas versões da história são negociadas por subjetividades singulares que se relacionam na cena e na tela e expõem, em seus testemunhos, versões dissidentes da memória oficial. Nesse caso, é a intimidade que coloca os termos do engajamento (Reinelt, 2011, p.21). Ou como observa Béatrice Picon-Vallin, trata-se da manifestação das vozes da "pequena história" vivida por homens e mulheres com suas verdades esparsas, subjetivas, obscuras e contraditórias (Picon-Vallin, 2019).

A visão estereoscópica da história é viabilizada por diversos estratos da assemblage cênica e por testemunhos de refugiados e indígenas de três diferentes continentes, além de fragmentos da Odisseia. Percebe-se que a circulação transnacional da memória em contextos transculturais acaba projetando uma rede da violência no mundo contemporâneo, que conecta Europa, África e América em distintas situações geográficas e históricas. Para o espectador é evidente que a constelação de histórias e corpos de 0 agora que demora pretende mapear diferentes formas de implicação da subjetividade em traumas coletivos e projetar uma memória multidirecional pela justaposição de relatos de guerra, espoliação neocolonial, crise de refugiados e extermínio de indígenas. Na projeção artística da memória coletiva, Christiane Jatahy consegue articular arquivos vivos, transnacionais e minoritários (Rothberg, 2013, p.40-41).

Sabe-se que a Odisseia de Homero não termina em Ítaca. No final da epopeia, após o retorno de Ulisses à ilha, o adivinho Tirésias o aconselha a partir em busca de seus ancestrais. Na tentativa de repetir e refazer o final da narrativa Christiane Jatahy decide recuperar o passado obscuro de seus antepassados e, por meio dele, a memória esquecida do Brasil. Dessa forma, ligando sua história pessoal à do país, a diretora volta a um episódio dramático da história familiar, quando um 
avião que transportava seu avô sofreu um acidente na Amazônia e jamais foi encontrado. Em busca de vestígios de sua morte, a artista viaja para o local em que o avião caiu na floresta, onde vivem os índios Kayapó. "É no encontro com homens e mulheres que ainda podiam ter a memória do que the aconteceu que eu queria concluir um espetáculo em que o retorno à casa de origem é um graal”, revela Jatahy (Sourd, 2019, p.19).

A cena final foi filmada na aldeia, em lugar próximo ao da queda do avião. No coração da floresta amazônica, as chamas de uma fogueira crepitam na noite e iluminam o rosto enrugado do chefe Kayapó. Jatahy relata que veio em busca dos rastros do avô desaparecido em 1953, em circunstâncias obscuras. Como seu corpo nunca foi encontrado, por muito tempo a família quis acreditar que ele havia sobrevivido entre os indígenas. É emocionante a passagem em que o velho cacique recorda-se da explosão do avião no passado, que ressoa na floresta de hoje, devastada por incêndios e a pilhagem das terras indígenas pelo agronegócio e pelas mineradoras internacionais.

O agora que demora termina com o depoimento dos Kayapós narrado em português intercalado à língua indígena, em que os membros da tribo prometem resistir à invasão dos fazendeiros que ocupam suas terras com o apoio do governo. No final do espetáculo, vemos um Kayapó às margens de um rio da Amazônia lendo o último episódio da Odisseia traduzido para sua língua. Ele afirma reconhecer na narrativa de Homero certas imagens da mitologia ameríndia. Nesse momento, Christiane Jatahy entra no palco para lembrar ao público que a Terra inteira tem responsabilidade sobre o que está acontecendo no mais profundo da floresta brasileira.

Desse modo, depois de atravessar uma constelação de sites de violência, a navegação transnacional dos refugiados termina com os povos nativos do Brasil, cujo genocídio continua de forma alarmante. O mapeamento de múltiplas formas de violência nos campos de refugiados do Líbano, da Grécia, da Palestina, da África do Sul e das aldeias indígenas do Brasil é capaz de criar um território transnacional onde é possível lembrar o passado e recuperar a memória no presente da cena, em que as lembranças suprimidas ganham espaço de manifestação. Talvez seja possível dizer que Nossa Odisseia é uma espécie de laboratório performativo 
destinado à reinvenção da memória, ao prover instrumentos para que o passado e o presente se interroguem e se afetem de forma crítica, na via de uma criação artística reconfigurada (Kuburovic e Heathfield, 2016). Assim, na tela do palco e na plateia, refugiados, indígenas, performers e espectadores negociam novas visões da história na intenção de projetar versões dissidentes na memória oficial.

\section{Referências}

ABRAMOVIC, Marina. Seven Easy Peaces. Milan: Charta, 2007.

AGAMBEN, Giorgio. Quel che Resta di Auschwitz. L'Archivio e il Testimone. Torino: Bollati Boringhieri, 1998.

AUSLANDER, Philipp. Liveness. Performance in a Mediated Culture. London e New York: Routledge, 1999.

AUSLANDER, Philipp. "The Performativity of Performance Documentation". In: JONES, Amelia Jones e HEATHFIELD, Adrian (ed.). Perform, Repeat, Record. Chicago: The University of Chicago Press, 2012, p.47-58.

CASSIN, Barbara. "L’Odyssée et le Jour du Retour”. In: BENJELLOUN, Nadia. Le Voyage Initiatique. Paris: Albin Michel, 2011, p.101-118.

DA COSTA, José, JATAHY, Christiane. L'Espace du Commun. Le Théâtre de Christiane Jatahy. Paris: Hachette, 2017.

DARGE, Fabienne. “Au Festival d'Avignon, Christiane Jatahy Présente son Odyssée Intérieure”. Le Monde, 5 de julho, 2019.

DELEUZE, Gilles, GUATTARI, Felix. L’anti-OEdipe: Capitalisme et schizophrénie. Paris: Les Editions de Minuit, 1972.

DERRIDA, Jacques. Mal d'Archive. Paris: Galilée, 1995.

DERRIDA, Jacques. Poétique et politique du témoignage. Paris: L’Herne, 2005.

DERRIDA, Jacques. Trace et archive, image et art. Paris: Ina Editions, 2014.

FÉRAL, Josette. Théorie et Pratique du Théâtre. Au-delà des Limites. Montpellier: l'Entretemps, 2011.

FISCHER-LICHTE, Erika. "Reality and Fiction in Contemporary Theatre". In: BOROWKSKI, Mateusz, SUGIERA, Malgorzata (ed.). Fictional Realities/Real Fictions. New Castle: Cambridge Scholars Publishing, 2007, p.13-28. 
FISCHER-LICHTE, Erika. The Transformative Power of Performance. Trad. Saskya e Iris Jain. London e New York: Routledge, 2008.

FORSYTH, Alison, MEGSON, Chris (ed.). Get Real. Documentary Theatre Past and Present. Basingstoke: Palgrave Macmillan, 2009.

FOUCAULT, Michel. Archéologie du Savoir. Paris: Gallimard, 1969.

GLUSBERG, Jorge. The Art of Performance. New York: New York University Press, 1980.

GOLDBERG, Rose-Lee. Performance Art. From Futurism to the Present. London: Thames and Hudson, 1988.

HANTELMANN, Dorothea von. How to Do Things with Art. Zurich: JRP/Ringier, 2007.

JATAHY, Christiane. Diálogos para a Criação de A Floresta que Anda. Rio de Janeiro: Cobogó, 2017.

KUBUROVIC, Branislava, HEATHFIELD, Adrian. "Being With Emergence". In WEE, Cecilia (ed.). Perform, Experience, Re-Live. London: Tate Public Programmes, 2016, p.200-222.

MARTIN, Carol. Theatre of the Real. Basingstoke: Palgrave Macmillan, 2013.

MARTIN, Carol (ed.). Dramaturgy of the Real on the World Stage. Basingstoke: Palgrave Macmillan, 2010.

MASSUMI, Brian. Politics of Affect. Cambridge: Polity Press, 2015.

MULLER, Martin. "Assemblage thinking and actor-networks: Rethinking Sociomaterial Power, Politics and Space". Geography Compass, No.9/1: 2015, p.27-41.

PHELAN, Peggy. Unmarked. The Politics of Performance. London e New York: Routledge, 1993.

PICON-VALLIN, Béatrice, MAGRIS, Erica (ed.). Les Théâtres Documentaires. Montpellier: Deuxième Époque, 2019.

ROTHBERG, Michael. "Multidirectional memory and the implicated subject: On Sebald and Kentridge". In: PLATE, L., SMELIK, (ed.). Performing Memory in Art and Popular Culture. New York e London: Routledge, 2013, p.35-58.

SCHECHNER, Richard. Performance Studies: An Introduction. London e New York: Routledge, 2002. 
SCHNEIDER, Rebecca. Performing Remains: Art and War in Times of Theatrical Reenactment. London e New York: Routledge, 2011.

SCHNEIDER, Rebecca. "Performance remains again”. In: GIANNACHI, Gabriela, KAYE, Nick, SHANKS, Michael (ed.). Archaelogies of presence. London e New York: Routledge, 2012, p.64-81.

SCHNEIDER, Rebecca. "Performance remains". In: JONES, Amelia, HEATHFIELD, Adrian (ed.). Perform, repeat, record. Chicago: The University of Chicago Press, 2012, p.137-150.

SCHNEIDER, Rebecca. "Performance and Documentation: Acting in Ruins and the Question of Duration”. In: DZIEWANSKA, Marta, LEPECKI, André (ed.). Points of Convergence. Alternative Views on Performance. Warsaw: Museum of Modern Art, 2017, p.65-84.

SOURD, Patrick. “Modernes Odyssées”. Les Inrockuptibles, 29 agosto 2019.

TAYLOR, Diana. The archive and the repertoire. Durham e London: Duke University Press, 2003.

TRIAU, Christophe. "Miroirs et Anamorphoses du Spectateur: A Floresta que Anda, de Christiane Jatahy”. Alternatives Théâtrales, No.131: 50-55.

WILMER, Stephen Elliot. Performing statelessness in Europe. Basingstoke: Palgrave Macmillan, 2018.

Recebido em: 11/10/2021

Aprovado em: 22/10/2021 